\title{
Investigating Students' Attitudes, Motives, Participation and Performance Regarding Out-of-Class Communication (OCC) in a Flipped Classroom
}

\author{
Tristan $\mathrm{Cui}^{1}$ and Andrew Coleman ${ }^{2}$ \\ ${ }^{1}$ Monash University, Melbourne, Australia \\ ${ }^{2}$ Swinburne University of Technology, Melbourne, Australia \\ tristan.cui@monash.edu \\ akc2165@gmail.com \\ DOI: 10.34190/JEL.18.6.007
}

\begin{abstract}
In a flipped classroom, students engage in active learning during class time and have individual informationtransmission outside class time. University students need to complete the pre/post-class activities to fully benefit from flipped classroom. It is important that teachers adopt practical methods including teacher-student out-of-classroom communication (OCC) to help students manage their time effectively and stay on task. This research examines the practice of $\mathrm{OOC}$ in a flipped first-year postgraduate Business Law course at an Australian university that comprises a large overseas student cohort. By means of a questionnaire, the researcher collected data about student perceptions of OCC, their motives for engaging in OCC, and the change of the motives in a flipped classroom. Student demographics, online participation, and academic performance data were exported from the university database. The student answers, participation, and performance were measured and compared with t-tests. The preliminary results show that in a flipped classroom, students were more motivated to engage in OCC. Moreover, the short-term online participation improved for the students who were communicated by the teacher outside classroom. However, an analysis of the data indicated no statistically significant difference in students' academic performance. In the concluding sections of this paper, the limitations of this study are acknowledged, followed by several recommendations for future research.
\end{abstract}

Keywords: Out-of-classroom communication (OCC), flipped classroom, motivation, intervention

\section{Introduction}

The "flipped classroom" is loosely defined as a method of instruction whereby individualised, direct instruction occurs outside the classroom, often assisted by information technology, while interactive learning activities occur inside the classroom (McNally, et al., 2017). The popularity of this concept has grown rapidly in recent years (Abeysekera and Dawson, 2015).

The approach, however, does have its drawbacks, particularly if the demands placed on students by the selfdirected part of a course are too extensive or onerous (Zainuddin and Halili, 2016). Therefore, careful consideration has to be given to the design of flipped units to ensure successful implementation. Various methods for improving unit designs, such as gamification and productive failure approaches, have been explored by educators, (Huang and Hew, 2018; Song and Kapur, 2017). However, there are very few studies on the use of Out-of-Class Communication (OCC) in conjunction with the flipped classroom in higher education.

Instructional design researchers have paid closer attention to concepts like OCC in recent years (Sung, 2018) as, increasingly, it has been recognised that much of a student's learning takes place outside of timetabled hours. In tertiary education, the value of OCC has been well-acknowledged in terms of increased student retention, persistence, and motivation (Brooks and Young, 2016). The application of OCC combined with a flipped classroom approach can influence the successful design and teaching of a unit. However, the application of OCC in a flipped classroom environment in higher education has not been closely observed and analysed. Thus, the aim of our research is to address this gap by examining the practice of OOC in a flipped first-year postgraduate Business Law course at an Australian university with a large cohort of overseas students.

Australian universities have enjoyed a boom in enrolments in the last decade (Australian Department of Education and Training, 2018). Increased student numbers have also brought challenges, particularly for teachers since it can be difficult to engage all learners and to monitor students' learning progress (Saunders and Gale, 2012). Compromises also need to be made regarding "personalised" communication, during both inclassroom and out-of-classroom teaching periods. 
The spike in enrolments is mainly due to the success of Australian universities in recruiting international students. According to the Australian Department of Education and Training (2017), about half of these overseas students are from Confucian Heritage Culture $(\mathrm{CHC})$ countries that include but are not limited to China, Vietnam, Japan, South Korea. However, a closer examination of individual units within specific universities, such as Law and Business Decisions at Monash University (Caulfield Campus), reveals a far greater percentage of international enrolments. For example, in the second semester of 2018 , of a total of 138 enrolments, $97 \%$ were international students. Although Monash has a diverse international student population, of that $97 \%$, approximately $78 \%$ (104) were from mainland China, or $75 \%$ of the entire cohort. Much has been written about the challenges faced by international students in the UK and the US (Heng, 2017; Kraal, 2017; Heng, 2018). The challenges faced by our cohort in Australia are similar. For example, there is the very real challenge of having to support themselves and study in a new country (Heng 2017; Kraal 2017; Heng 2018). However, the greatest challenge is the language barrier experienced by English as Second Language (ESL) students. Whilst the English language entry requirement is 6.5 (IELTS), the faculty concluded from observations of their students in class that many students were experiencing serious challenges with verbal and/or written communication - a concern expressed by many of the students themselves at the beginning of each semester.

The next challenge, which exacerbated the problems caused by the language barrier, is the nature of law units. Law is a language-intensive discipline with nuances of usage that challenge native speakers, and contain concepts such as "reasonable" that are value-laden and culturally relative. Law units involve solving problems that are laden with varying degrees of uncertainty. Many domestic students from a STEM or accounting background struggle with this problem since their disciplines demand an unequivocal right or wrong answer, whereas in law there is no right or wrong answer- just a better argument. Thus, answering a legal problem-style question requires not only knowledge of concepts, but also finely-tuned language skills.

Finally, for cultural reasons, many students from these backgrounds tend to avoid communication if they feel their language skills are deficient, for fear of "losing face" (Teo and Arkoudis, 2019). Moreover, several researchers have found that some overseas students are surprised that they do not feel more welcome during their studies abroad. This gives rise to other communication complications when students become frustrated by the lack of curiosity about them and their culture, unlike the way that foreigners are treated back in their home countries (Leask and Carroll, 2011). Also, for many students from CHC backgrounds, the fact that they are not familiar with the new education system and culture makes it more difficult for them to participate in interactive learning and communication activities with their classmates and teachers. This is because the learning models with which they are familiar in their native cultures are more didactic-based, authority-centred, and with less interaction between teachers and learners (Hodkinson and Poropat, 2014).

To answer the challenges posed by the increasing student numbers in the class and the large proportion of international students in the flipped (law) unit, personalised emails were sent to a large number of students throughout the semester-. Using the Student Relationship Engagement System (SRES; www.sres.io), the teacher was able to sort students into different groups according to data such as workshop attendance, online participation in the Learning Management System (LMS) and assessment outcomes. Emails were sent in bulk, albeit with personalised information. In these personalised emails, the teacher often encouraged the learners to communicate with them. The efforts from the teacher initiated and promoted OCC in this class.

\section{Literature review}

The flipped classroom has been defined by Abeysekera and Dawson (2015) as a set of pedagogical approaches that:

- move most information-transmission teaching out of class

- use class time for learning activities that are active and social

- $\quad$ require students to complete pre- and/or post-class activities to fully benefit from in-class work.

The flipped classroom approach promotes active learning strategies by using classroom time to engage students in activities related to the higher levels of Bloom's taxonomy (Nouri 2016). Some researchers have claimed that it can bring positive outcomes for university student learning in terms of increased learning, more effective learning, and improved student outcomes as it enables students to learn at their own pace by watching lecture videos. Also, students benefit from not only the more practical and interactive classroom learning coordinated by the teacher, but also from the more scaffolded learning processes supported by the teacher and the 
classmates both in the classroom and in the online learning space (Nouri, 2016; Thai, De Wever, and Valcke, 2017).

Scholarly studies related to the flipped classroom often adopt the self-determination theory (SDT), to investigate its relationship to student motivation to learn (Abeysekera and Dawson, 2015). The SDT defines the three basic cognitive needs as the needs for competence, autonomy, and relatedness (Ryan and Deci, 2000). People feel competent regarding know-how mastery, feel in control of their own study pace, and feel related when working in a group (Ryan and Deci, 2000). Thus, the flipped classroom approach might improve student motivations, both intrinsic and extrinsic, as it creates such scenarios for students. And if the students are more motivated, they might be willing to complete a significant amount of learning activities both inside and outside the classroom. Some researchers claim that the flipped classroom motivated students to learn during the lessons themselves (Clark, Kaw, and Besterfield-Sacre, 2016) as well as in their subsequent learning activities (McLaughlin et al., 2013).

Furthermore, various other beneficial effects of the flipped classroom method of teaching and learning have been found by previous researchers. Studies have strongly argued that students have engaged readily in flipped classrooms, possibly because they were more prepared and more confident during active learning in the classroom as they had watched pre-class lecture videos (Zainuddin and Halili, 2016; Lo and Hew, 2019; He et al., 2019). Furthermore, when Hung (2015) investigated the student interactions in a flipped classroom, $64 \%$ of the participants reported having increased their interaction with the teacher and their classmates. With its positive impacts on students' motivation, engagement, and interaction, it is unsurprising that the flipped classroom design has been identified in some journal articles as a more effective means of improving students' performance in various subjects (Zainuddin and Halili, 2016). Study results also suggest that, compared with the traditional mode of delivering courses, students could improve their academic performance in a flipped classroom if they use the out-of-class learning materials prior to classes (Huang and Hew, 2018).

Despite the reported benefits of adopting a flipped classroom, researchers also noted that there are challenges (Huang and Hew, 2018). Many students claimed that they found it difficult to adjust to the new and unfamiliar flipped classroom approach and the pre- and post-class materials were too much for them to finish on time. At the same time, student engagement with the pre-class preparation learning resources and activities had a direct, positive effect on the success of the flipped class (O'Flaherty and Phillips, 2015). However, simply preparing welldesigned pre-class and post-class materials and tasks does not necessarily guarantee that the learners are going to complete them. Furthermore, students not completing the pre-class learning before the face-to-face sessions might compromise the intended outcomes of the flipped design.

To answer the challenges in flipped classrooms, course designers try to ensure that the pre- and post-class learning materials are aligned with and complement the in-class activities so that the students find the materials meaningful and useful. Moreover, lecture videos can be presented in innovative and interactive formats to attract and engage students. Some educators (Huang and Hew, 2018) have even begun to explore the application of gamification in the design of flipped classrooms to inspire learners to acquire knowledge via the out-of-class learning activities. Researchers have also explored effective change management strategies to minimise the risks associated with flipped classroom pedagogy (Hutchings and Quinney, 2015). However, to date, the role of out-of-classroom communication (OCC) and its influence on the success or otherwise of a flipped classroom has not been studied in depth.

OCC, defined as "student-faculty communication in the instructor's office, informally on campus, or before and after class" (Jaasma and Koper, 2002, p. 119), can occur via different modes (online, phone call, social media, text message, face-to-face, LMS forum), can be initiated by either student or teacher, can vary in content (course-related, personal problems, small talks, intellectual ideas), and can vary in duration (no durative/backand-forth conversation, a brief exchange, some lengthy conversations). However, in higher education, students might not engage in discussions with their teachers other than during the scheduled teaching hours. As Brooks and Young (2016) found in their research, college students do not think that they communicate with teachers often outside classroom. And even when they did, they were least likely to have lengthy conversations with their teachers.

Literature in the communication and education fields claims that that whether or not the students initiate or participate in OCC is influenced by the class dynamics, the teacher's method of teaching, and the teacher's 
personality (Leach and Wang, 2015). Students are more likely to initiate or participate in OCC with more attractive, credible, immediate, accessible teachers who have a sense of humour and are prepared to selfdisclose and use affinity-seeking strategies. Conversely, students are less likely to engage in OCC with a teacher who is verbally aggressive and strongly assertive, or when they have difficulty in securing OOC, fail to see the value of it, or have other more appropriate and convenient alternatives (Leach and Wang, 2015). Instructional communication researchers suggest that by using OCC, teachers can bring about positive education outcomes (Nadler and Nadler, 2001). Those positive outcomes have been observed in increased student higher education aspirations, affirmation, confidence, academic and cognitive development, persistence, and university retention (Faranda, 2015). The findings from those research studies consolidate the belief that many educators have: the productive casual talks between teachers and learners outside class time have a profound and beneficial effect and are positively related to the university students' educational experience (Myers, Martin, and Knapp, 2005).

Hence, the investigation of student motives to engage in communication with their teachers has become a focus of communication and education research. Researchers have described the students' motives for communication as deriving from "the needs students desire to have fulfilled through communication with their instructors" (Myers, et al., 2007, p. 496). University students have been asked why they would communicate with their teachers. The researchers identified five underlying reasons or motives: relational (desire to establish a personal relationship), functional (requiring information), excuse (wanting to justify faults), participation (wanting to appear engaged with learning), and sycophancy (wanting to flatter or charm) (Martin, Myers, and Mottet, 1999). Of these five reasons, researchers suggest that students might benefit more from the relational and participation motives as the students with those reasons are more motivated, satisfied, and associated, showing more participation, less challenging behaviour, and greater cognitive learning (Goodboy and Myers, 2008). In other studies which focus on the OCC via emails, the motives for students to engage in OCC with the teachers was measured using the instrument developed by Waldeck, Kearney, and Plax (2001). In those studies, the researchers found that students engage in the communication for the purposes of clarification, efficiency, and personal or social motives; they suggested that students are more likely to participate in OCC because they need clarification regarding some aspect of the course (Waldeck, Kearney, and Plax, 2001; Young, Kelsey, and Lancaster, 2011). Similarly, research has also been done on university students' motives for pursuing out-ofclassroom communication with the faculty academic advisor (Leach and Wang, 2015).

Similar to a traditional classroom environment, $\mathrm{OOC}$ in a flipped class can take place in a formal consultation, phone conversation, text messages, online forum, emails, or informal campus locations. Compared to the lecture and tutorial teaching format, a flipped classroom course might reduce the number of weekly in-class face-toface sessions between students and teachers. However, it is also supposed to promote more interactive and problem-based learning during the face-to-face interaction, which might lead to more teacher-student inclassroom communication (Abeysekera and Dawson, 2015). In those classes, the teachers coordinate the activities and provide immediate feedback instead of simply lecturing in front of the classroom. In university classes, the online learning spaces in the LMS also provide a convenient communication channel for teacher and students during the pre-class and post-class learning (Furse, Ziegenfuss, and Froehlich, 2018). The addition of the online learning platforms in the flipped classroom might influence the pattern of OCC between teachers and students. This study aims to acquire a better understanding of OCC in higher education and investigate OCC as a factor that has the potential to improve the design of courses for a flipped classroom.

Furthermore, educators and scholars have analysed the gender differences in terms of OCC (Jaasma and Koper, 2002). Some of the studies (Bennett, 1982; Nadler and Nadler, 2001), examining the frequency with which male and female students engaged in OCC with their teachers, have reported conflicting results. Bennett's study (1982) found that while there was no difference in OCC patterns in terms of student gender, the teacher's gender played a role in OCC as the female teachers received more OOC than did the male teachers. In another research, no major difference was found for teacher gender, but female students reported a lower frequency of OCC compared to the male students (Nadler and Nadler, 2001). This current study will also explore this OCC issue by addressing student perceptions of OCC frequency and motives in a flipped classroom environment.

In summary, the flipped classroom approach has positive impacts on students' motives, interactions, and performance in terms of active learning but it also has challenges when it comes to students being asked to complete pre- or post-class study activities designed to produce satisfying learning outcomes. OCC offers various benefits to students' learning experience, and it can be a useful addition to the course design in a flipped classroom approach. Such designs and applications in the emerging flipped classroom teaching strategy in higher 
education are still to be fully explored. To address this gap, the researchers examine the role of OCC in a flipped course.

\subsection{Research questions:}

1. What are the reasons for students engaging in OCC in a flipped classroom?

2. What are the influences of flipped classrooms on the students' motives to engage in OCC compared to the traditional pedagogical practices?

3. Does a personalised OCC initiated by the teacher have an impact on students' online participation in preclass and post-class learning activities in LMS in a flipped classroom?

4. Does a personalised OCC initiated by the teacher improve student performance in the flipped unit?

\section{Methodology}

In this study, quantitative data was collected from student surveys, learning management system logs, and the student database. Descriptive statistics, one-sample and independent t-tests, and paired t-tests were applied to analyse the data to investigate OCC in this business law class.

During the semester, the teacher communicated 15 times with the whole class via the LMS and tried to establish personalised OCC with individual students as well. Via the Student Relationship Engagement System (SRES; www.sres.io), the teacher filtered students based on their record for online learning activities and assessment results, then emailed them with personalised greeting and messages in bulk, in a total of four rounds:

1. 19 emails before the $1^{\text {St }}$ assessment,

2. 23 emails after the $1^{\text {st }}$ assessment,

3. 17 emails before the $2^{\text {nd }}$ assessment,

4. 38 emails after the $2^{\text {nd }}$ assessment.

Via emails, the teacher reminded students about overdue online learning activities, congratulated some students on their assessment scores, or encouraged the students to meet for consultations. In total, 74 students received personalised emails from the teacher at least once during the semester.

In summary, the researchers presented a flipped unit with plenty of student-teacher OCC. At the end of the semester, a post-course survey was conducted to determine students' OCC mode, motives for communicating, and the influence of the flipped classroom on students' motives for engaging in OCC.

\subsection{Participants}

In 2018, 133 international students (female: 95, male: 38) and 4 domestic students (female:2, male: 2) were enrolled in the first-year postgraduate business law unit in a large university in a metropolitan city in Australia. Of these students, 38 (27.7\%), comprising 31 females and 7 males, returned the questionnaire successfully. They were overseas students from five countries: 32 students (84.2\%) from China, 3 students (7.9\%) from Vietnam, 1 student (2.6\%) from India, 1 student (2.6\%) from Thailand, and 1 student (2.6\%) from Turkey. The students ranged in age from 22 to $37(M=25.24, S D=2.94 \%)$.

\subsection{Instruments}

\subsubsection{Out-of-Classroom Communication:}

The items in the survey questionnaire were intended to give us a better understanding of the participants' OCC with the teachers. The five-item measure in the research on teachers' email frequency conducted by Young, Kelsey, and Lancaster (2011) was modified to measure the OCC frequency. A modified version of the Brooks and Young (2016) measure of OCC type, location, and duration was also adopted.

\subsubsection{Motives/reasons to communicate:}

The motives for students to engage in the OCC with the teacher were measured using a modified 5-point Likerttype version of the students' reasons for emailing their teacher (Waldeck, Kearney, and Plax, 2001; Young, Kelsey, and Lancaster, 2011). Two new questions were included to replace the not-needed efficiency motives; these new items were intended to measure the students' motives for replying to or engaging in a communication initiated by the teacher, which was not measured by the original instrument. The 15 possible motives were categorised under three factors in this multidimensional measurement: personal and social motives for engaging in OCC (e.g., to let the teacher know I'm interested in the course), clarification and procedural motives (e.g. to 
ask the teacher questions about the course content), and responsive motives (e.g. to reply to a personal message/conversation to me started by my teacher).

\subsubsection{Flipped classroom's influence on motives to communicate:}

Unlike the more commonly-used university lecture and tutorial approach, a flipped classroom moves most information-transmission teaching out of class and uses class time for active and social learning activities (Abeysekera and Dawson, 2015). Often it provides more opportunities for teachers and students to work interactively within the classroom.

To investigate the influence of the flipped classroom on the students' motives for engaging in OCC, compared to the traditional lecture and tutorial teaching method, participants were also asked to indicate whether their motives changed in this flipped class.

\subsubsection{LMS records:}

In this flipped unit, the teacher created weekly online pre-class and post-class learning activities, including lessons and quizzes for 13 weeks in the LMS. Students' online activities and assessment grades were collected from their LMS records.

\section{Results and discussion}

Students reported how their teacher communicated with the whole class $(M=3.87, S D=1.19)$ and individually with the student $(M=3.39, S D=1.31$ ) outside classroom time, on a Likert-type scale ranging from 'hardly ever' (1) to 'numerous times' (5) in Table 1. An independent-samples t-test shows that there is a significant difference between how male students and female students reported on the frequency of teacher's OCC with the whole class ( $p=<0.05$ ) but not the frequency of individual OCC ( $p=0.306)$. Male students tend to consider 15 LMS announcements per semester a quite high number.

Table 1: Frequency of OCC for the whole class and individual students

\begin{tabular}{|l|l|l|l|l|l|}
\hline & Sex & $\mathbf{N}$ & Mean & Std. deviation & Std. error mean \\
\hline \multirow{2}{*}{ Class } & Male & 7 & 4.57 & .787 & .297 \\
\cline { 2 - 6 } & Female & 31 & 3.71 & 1.216 & .218 \\
\hline \multirow{2}{*}{ Individual } & Male & 7 & 3.86 & 1.464 & .553 \\
\cline { 2 - 6 } & Female & 31 & 3.29 & 1.270 & .228 \\
\hline
\end{tabular}

Most students reported their primary OCC mode with their teacher is email ( $n=30,78.9 \%)$, followed by face-toface $(n=5,13.2 \%)$, and the Moodle discussion forum $(n=3,7.9 \%)$. The significant role that email played in OCC shows that online written communication was more popular than face-to-face or voice communication. However, the result also brought to our attention that the flipped unit was not effective in engaging the student in online discussion forums, which should demonstrate active students' discussions with the teacher and their classmates. Furthermore, the duration of students' communication with their teacher was reported as: some lengthy conversation (e.g., more than 15 minutes of vocal talk or multiple text-based exchanges over an extended period of time) ( $n=14,36.8 \%)$, a brief exchange ( $n=14,36.8 \%)$, and no durative/back-and-forth conversation $(n=10,26.4 \%)$. Students tended to communicate with their teacher via email rather than face-toface.

Although the male and female students did not report any significant difference between the frequency of the teacher's OCC with the students individually, there was a significant difference between the reported frequency of the teacher's OCC addressing the whole class between male and female students. The male students were more likely than females to consider that 15 LMS announcements were "numerous times". Whether this attitude might make them more likely to ignore the teacher's message in the LMS needs further investigation.

\subsection{What are the reasons for students engaging in OCC in a flipped classroom?}

As displayed in Figure 1, the participants agreed that all the factors were important (mean score $>3$ ) for them to engage in OCC communication with their teacher, except one factor: to escape or divert from other tasks $(M=2.87)$. Moreover, there was no statistically significant difference between the answers of male and female students. 


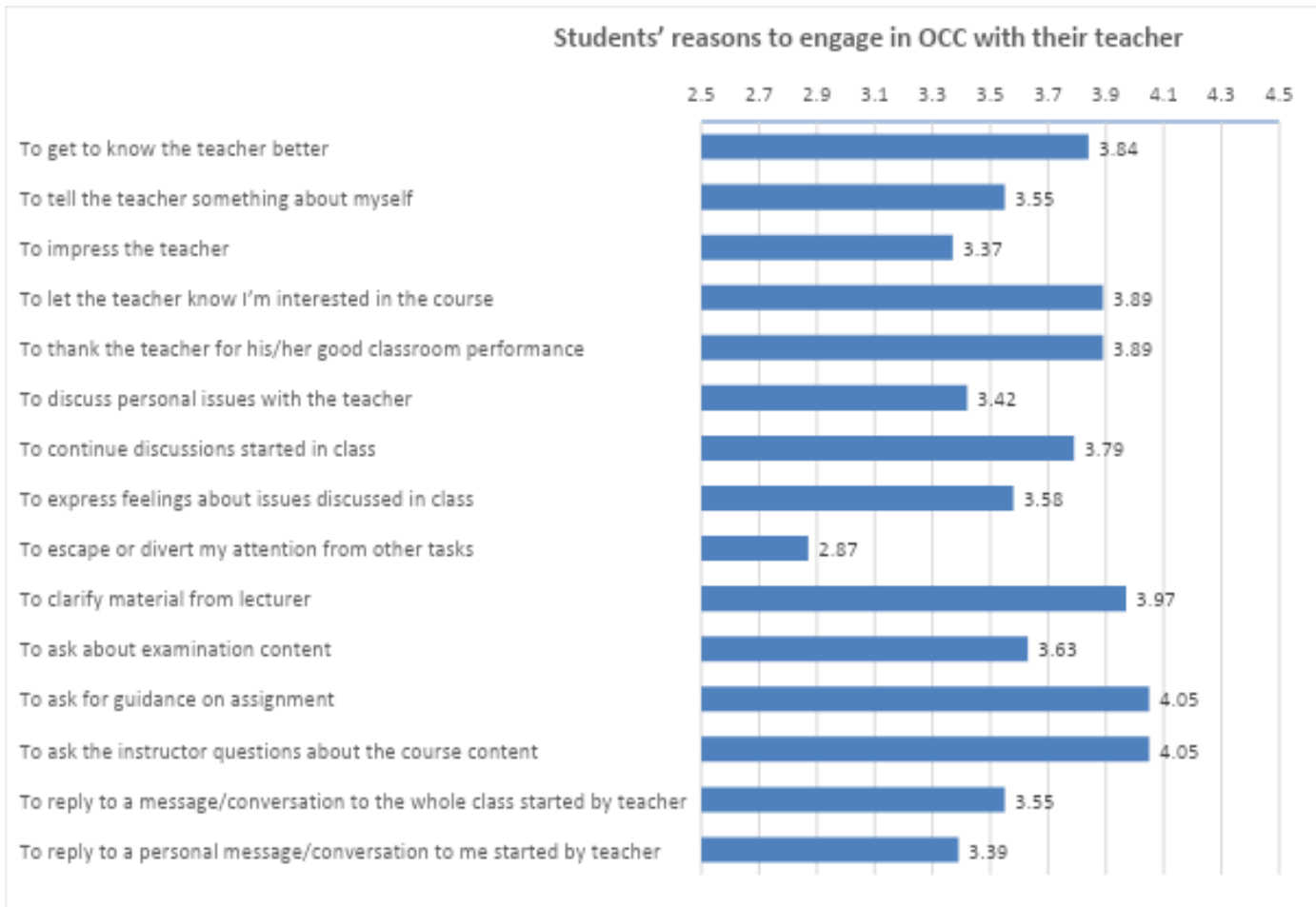

Figure 1: Students' reasons for engaging in OCC with their teacher

The students in this flipped class identified their three most important motives for communicating with their teacher outside the class time as:

- $\quad$ to ask guidance on assignment $(\mathrm{M}=4.05)$

- $\quad$ to ask the teacher about the course content $(M=4.05)$

- to clarify material from the teacher $(M=3.97)$

In a survey of 289 undergraduate students in the US regarding their motives for engaging in OCC, Waldeck, Kearney, and Plax (2001) found "that students reported a greater reliance on using e-mail to contact their teacher for procedural or clarification reasons" (p. 63). These findings were supported by those of this study which found that in an Australian university, postgraduates engaged in OCC with their teacher to seek clarification or for procedural reasons. Our results show that although detailed instructions for assignments in this flipped classroom were included in the LMS together with learning resources such as lecture videos, online lessons, and reading materials, students still felt strongly about receiving personalised advice from the teacher on assignments, and clarification about the course contents. Perhaps, no matter what the pedagogical or technological solution is proposed, a central tension will remain between presenting larger-scale lectures, and students' expectations of personalised contact with the teacher. Hence, the change of course design in the flipped classroom does not alter students' main motive for communicating with their teacher.

The participants also indicated their three less important reasons:

- to escape or divert from other tasks $(M=2.87)$

- $\quad$ to impress the teacher $(M=3.37)$

- to reply to a personal message/conversation to me started by my teacher $(\mathrm{M}=3.39)$

The results show that personal and social motives are less important reasons for students wanting to engage in OCC, which is similar to the findings of Waldeck, Kearney, and Plax (2001). Even if the teacher initiated personal OCC with individual students, the motive to respond to this communication is still less important to the students than are their other motives ( $M=3.39)$.

\subsection{What are the influences of flipped classrooms on the students' motives to engage in OCC compared to the traditional pedagogical practices?}

As shown in Figure 2, students reported an increase in all the motives when learning in a flipped classroom, compared to the traditional setting. 
The students in this flipped class identified their three most increased motives for communicating with their teacher outside the class time compared to a traditional lecture and tutorial approach:

- $\quad$ to ask guidance on assignment $(\mathrm{M}=4.18)$

- $\quad$ to ask the teacher about the course content $(M=4.11)$

- to thank the teacher for his/her good classroom performance $(M=4.03)$

A closer analysis using the one sample t-test showed that the mean scores for the motive changes are significantly different from the middle-value 3 at significant level except for the motive to 'escape or divert my attention' ( $p=0.277$ ) and 'to reply to a personal message/conversation to me started by my teacher' $(p=0.077)$. There was no statistically significant difference between the answers of male and female students.

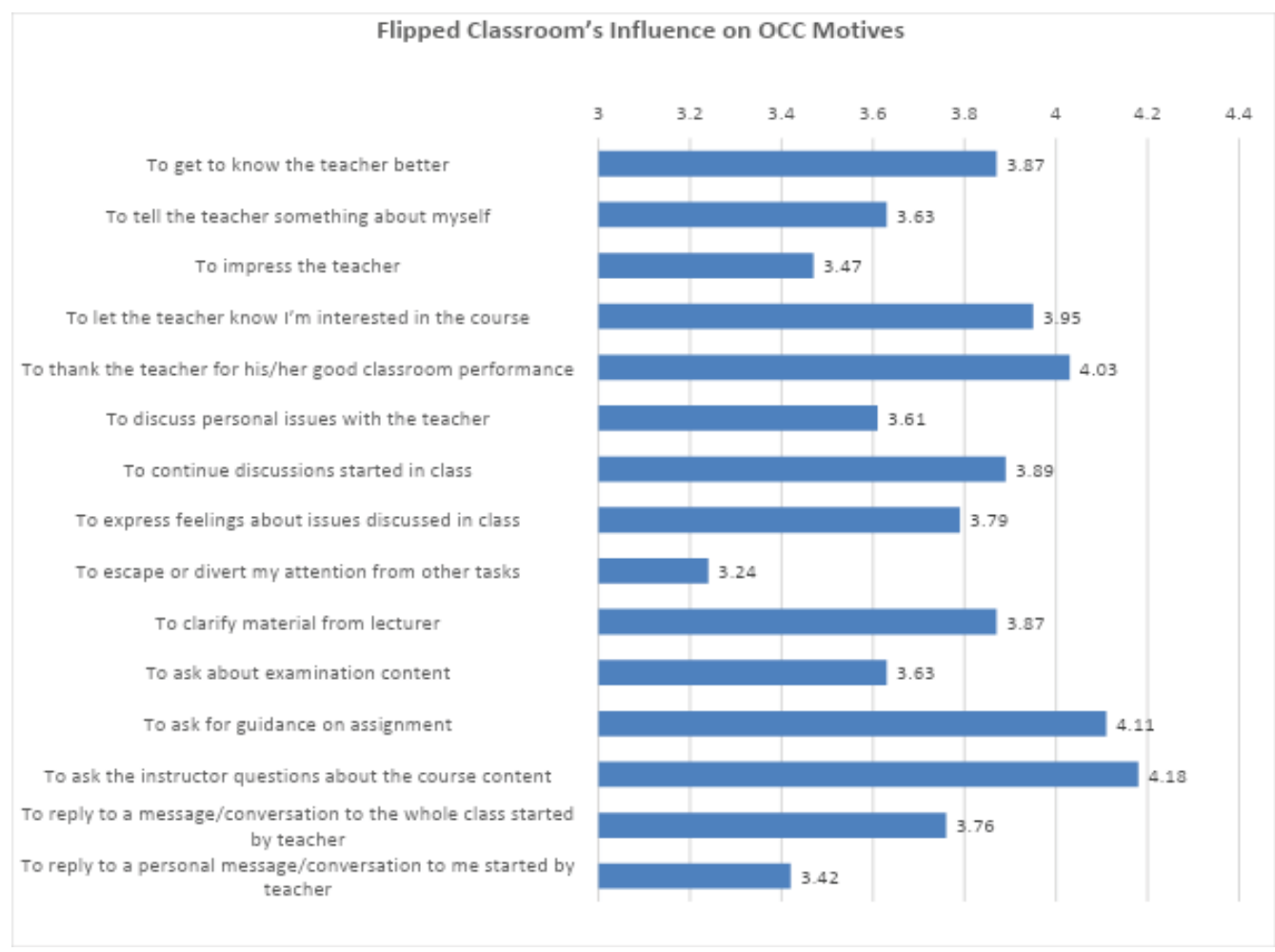

Figure 2: Influence of flipped classroom on OCC motives

Because no actual lecture time is allocated in the flipped unit, students might be unsure of the assignment requirements or course contents if they are not actively engaged with the online learning resources and activities. This may account for the increase in motives to ask for guidance on assignments and clarification about the course content. And in the flipped unit, student could become more actively engaged in the higher order thinking according to Bloom's taxonomy (Anderson, et al., 2001). Therefore, they tried to learn deeper into the subject by asking the teacher for more information. Further research is needed to find out the cause of those changes. The motive to thank the teacher for his/her good classroom performance also was reported to increase significantly. It would be interesting to find out whether that was a result of a more engaging, interactive, and student-centred course design in a flipped classroom approach.

\subsection{Does a personalised OCC initiated by the teacher have an impact on students' online participation in pre-class and post-class learning activities in LMS in a flipped classroom?}

The teacher sent emails to the 19 of the 137 enrolled students who had not completed more than four of the set activities. Such communication was designed to encourage them to learn more actively online and improve their academic performance, especially for the first assessment task in week 5.

An independent samples t-test was conducted to compare the number of newly-completed activities and percentage of newly completed activities between students who had missed more than four activities (received email) and students who had missed fewer than four activities (no email received). Results are presented in 
Table 2. The students who received the teacher's email had completed more of the overdue learning activities before the next assessment.

Table 2: Newly completed activities number and percentage

\begin{tabular}{|c|c|c|c|c|c|}
\hline & Received email & No email received & $\mathbf{t}$ & p-value & df \\
\hline \multirow{2}{*}{ Newly-completed activities } & $M=2.79$ & $M=0.78$ & \multirow{2}{*}{7.24} & \multirow{2}{*}{$<0.001$} & \multirow{2}{*}{91} \\
\hline & $S D=1.84$ & $S D=0.78$ & & & \\
\hline \multirow{2}{*}{ Newly-completed percentage } & $M=52 \%$ & $M=42 \%$ & \multirow{2}{*}{1.13} & \multirow{2}{*}{0.268} & \multirow{2}{*}{32.1} \\
\hline & $S D=0.35$ & $S D=0.41$ & & & \\
\hline
\end{tabular}

\subsection{Does a personalised OCC initiated by the teacher improve student performance in the flipped unit?}

In total, the teacher sent 19 individual emails to students to remind that they had completed only few of the online learning activities, and to encourage them to finish more or seek consultation to prepare for the coming assessment. Within the week between the email communication and the first test, 11 students (Group A) had finished only less than half of the overdue online learning activities, while eight students (Group B) had completed $50 \%$ or more.

When comparing the results of the 1st assessment (week 5), 2nd assessment (week 9), and the final marks obtained by Groups A and B (Table 3 ) in this flipped unit, there is no statistically significant difference in their performance.

Table 3: Comparison of assessment results and final end-of-semester results

\begin{tabular}{|c|c|c|c|c|c|c|}
\hline & \multicolumn{2}{|c|}{ Test 1 Result (15 marks) } & \multicolumn{2}{|c|}{ Test 2 Result (20 marks) } & \multicolumn{2}{|c|}{ Semester Result (100 marks) } \\
\hline & Group A & Group B & Group A & Group B & Group A & Group B \\
\hline $\mathbf{N}$ & 11 & 8 & 11 & 8 & 10 & 8 \\
\hline Mean & 10.09 & 10.13 & 11.53 & 12.78 & 55.70 & 57.13 \\
\hline Std. deviation & 2.77 & 1.55 & 2.11 & 1.64 & 4.87 & 8.32 \\
\hline t-test & \multicolumn{2}{|l|}{0.31} & \multicolumn{2}{|l|}{1.38} & \multicolumn{2}{|l|}{0.46} \\
\hline$p$-value & \multicolumn{2}{|l|}{0.97} & \multicolumn{2}{|l|}{1.67} & \multicolumn{2}{|l|}{0.68} \\
\hline
\end{tabular}

\section{Conclusions}

In this research, the students agreed that all of the reasons for engaging in OCC were important except one: to escape or divert from other tasks. They also agreed that the procedural and clarification reasons were more important than the personal and social motives. Our results are consistent with the findings obtained in the previous research of undergraduate students (Waldeck, Kearney, and Plax, 2001). The data show that even if the teacher initiated personal OCC with individual students and observed an increase of students coming to consultations, the motive to respond to this communication is still relatively lower $(M=3.39)$. This could discourage teachers from initiating OCC with their students and in the hope of receiving a response. The analysis did not find any significant difference between the responses of male and female students.

The investigation results show that the participants considered their motive to engage in OCC increased in a flipped classroom approach compared to the traditional university lecture and tutorial approach except for two motives: 1 . to escape or divert my attention, and 2. to reply to a personal message/conversation initiated by my teacher. Findings showed a substantial increase in the number of students using OCC to thank the teacher for their good classroom performance. In this project, the teacher did convert the face-to-face class into a more interactive, problem-based, and student-focused sessions so that the learners could engage in higher order learning according to Bloom's taxonomy (Anderson et al., 2001), which is not possible in traditional teachercentred sessions. The teacher's changing role from lecturer to facilitator of learning might be well received by the students. And that could explain the increase in students using OCC to thank the teacher. On another note, 
students in the flipped classroom also thought they were increasingly motivated to engage in OCC in order to clarify course contents and assignment tasks. Considering the previous research findings that sometimes students had difficulties in completing self-learning tasks outside classroom time (Zainuddin and Halili, 2016), such students would be more likely to communicate with the teacher for clarification reasons because they are unsure of what the self-learning tasks require.

The most significant increase was in the students' motivation to ask for guidance on assignment tasks and to ask the teacher about the course content. This could be the result of the student being unfamiliar with the assignment requirements or course content, and there being no lecture time allocated to the flipped unit. Another possible reason may be that students tried to seek more information regarding the course contents from the teacher as they were more actively engaged in higher order learning in the flipped classroom. Further research is needed to determine the cause of such changes. As students reported using email as their primary method to communicate with the teacher out-of-classroom, it would also be interesting to discover whether those international students whose first language is not English, used written communication such as email to replace the more challenging face-to-face interaction with the teacher. Also, researchers could investigate the different influence of OCC delivery modes and formats as a flipped classroom integrated with extensive elearning context offers a variety of modalities to communicate with students.

The study results of the LMS data of the student online participation show that even though there was no statistically (percentage) significant difference in the newly completed activity out of the total overdue activities between the students who received the teacher's reminder email ( $<=50 \%$ of the activities by week 4 ) and those who did not ( $>50 \%$ activities by week 4 ), the students who received the email had completed a significantly greater number of online learning activities in the following week before the first major assessment. Considering that all students who received the email had a record of missing the scheduled learning activities, it is evident that the communication from the teacher had encouraged the students to participate in the online learning more actively in the short-term (a week). Our research results are not consistent with those of previous research which investigated the whole-semester participation (Sullivan, 2016). Further investigation might be needed to understand the short-term and long-term effects, on student participation, of teachers' OCC.

In this research, results indicated that there was no significant difference in student performance outcomes regardless of whether or not they engaged in online learning activities after receiving personalised communication from their teacher. The researchers feel that the current unit design limited the research design options. It would be ideal if future research could employ a control group for an experimental study with large student numbers to test whether there is any correlation between students' OCC and their academic performance in a flipped classroom.

\section{Acknowledgements}

The authors would like to thank Hazel Tan, Graham Parr, Shane Phillipson, Scott Bulfin, Claudia Orellana-Farias, and Christian Swanwick of Monash University for providing comments on earlier drafts of this manuscript.

\section{References}

Abeysekera, L., and Dawson, P., 2015. Motivation and cognitive load in the flipped classroom: definition, rationale and a call for research. Higher Education Research and Development, 34(1), pp. 1-14. doi:10.1080/07294360.2014.934336

Anderson, L. W. e., Krathwohl, D. R. e., Airasian, P. W. c., and Bloom, B. S., 2001. A taxonomy for learning, teaching, and assessing: a revision of Bloom's taxonomy of educational objectives. New York: Longman.

Australian Department of Education and Training, 2017. 2017 Section 7 overseas students. Canberra: Australian Department of Education and Training.

Australian Department of Education and Training, 2018. 2018 First half year student summary time series. Canberra: Australian Department of Education and Training.

Bennett, S. K., 1982. Student perceptions of and expectations for male and female instructors: evidence relating to the question of gender bias in teaching evaluation. Journal of Educational Psychology, 74(2), pp. 170-179. doi:10.1037/0022-0663.74.2.170

Brooks, C. F., and Young, S. L., 2016. Exploring communication and course format: conversation frequency and duration, student motives, and perceived teacher approachability for out-of-class contact. International Review of Research in Open and Distance Learning, 17(5), pp. 235-247.

Clark, R. M., Kaw, A., and Besterfield-Sacre, M., 2016. Comparing the effectiveness of blended, semi-flipped, and flipped formats in an engineering numerical methods course. Advances in Engineering Education, 5(3), pp. 1-38. 
Faranda, W. T., 2015. The effects of instructor service performance, immediacy, and trust on atudent-faculty out-of-class communication. Marketing Education Review, 25(2), pp. 83-97.

Furse, C., Ziegenfuss, D. H., and Froehlich, A. L., 2018. Teach-flipped: a faculty development MOOC on how to teach flipped, ASEE Annual Conference and Exposition, Conference Proceedings 2018, Salt Lake City, Utah, USA.

Goodboy, A. K., and Myers, S. A., 2008. The effect of teacher confirmation on student communication and learning outcomes. Communication Education, 57(2), pp. 153-179. doi:10.1080/03634520701787777

He Y, Lu J, Huang H, He S, Ma N, Sha Z, et al. (2019) The effects of flipped classrooms on undergraduate pharmaceutical marketing learning: a clustered randomized controlled study. PLoS ONE 14(4): e0214624. https://doi.org/10.1371/ journal.pone.0214624

Heng, T.T., 2018. Different is not deficient: contradicting stereotypes of Chinese international students in US higher education, Studies in Higher Education, 43 (1), pp. 22-36.

Heng T. T., 2017, Voices of Chinese students in USA colleges: 'I want to tell them that... ', Studies in Higher Education, 42(5), pp.833-850.

Hodkinson, C. S., and Poropat, A. E., 2014. Chinese students' participation: the effect of cultural factors. Education and Training, 56(5), pp. 430-446.

Huang, B., and Hew, K. F., 2018. Implementing a theory-driven gamification model in higher education flipped courses: effects on out-of-class activity completion and quality of artifacts. Computers and Education, 125, pp. 254-272. doi:10.1016/j.compedu.2018.06.018

Hung, H.-T., 2015. Flipping the classroom for English language learners to foster active learning. Computer Assisted Language Learning, 28(1), pp. 81-96.

Hutchings, M. and Quinney, A., 2015. The flipped classroom, disruptive pedagogies, enabling technologies and wicked problems: responding to"the bomb in the basement". Electronic Journal of e-Learning, 13(2), pp.106-119.

Jaasma, M. A., and Koper, R. J., 2002. Out-of-class communication between female and male students and faculty: the relationship to student perceptions of instructor immediacy. Women's Studies in Communication, 25(1), pp. 119-137. doi:10.1080/07491409.2002.10162443

Kraal, D., 2017. Legal teaching methods to diverse student cohorts: a comparison between the United Kingdom, the United States, Australia and New Zealand. Cambridge Journal of Education, 47 (3), pp. 389-411

Leach, R. B., and Wang, T. R., 2015. Academic advisee motives for pursuing out-of-class communication with the faculty academic advisor. Communication Education, 64(3), pp. 325-343.

Leask, B., and Carroll, J., 2011. Moving beyond 'wishing and hoping': internationalisation and student experiences of inclusion and engagement. Higher Education Research and Development, 30(5), pp. 647-659. doi:10.1080/07294360.2011.598454

Lo, C.K. and Hew, K.F., 2019. The impact of flipped classrooms on student achievement in engineering education: a metaanalysis of 10 years of research. Journal of Engineering Education, 108(4), pp. 523-546.

Martin, M. M., Myers, S. A., and Mottet, T. P., 1999. Students' motives for communicating with their instructors. Communication Education, 48(2), pp. 155-164. doi:10.1080/03634529909379163

McLaughlin, J. E., Griffin, L. M., Esserman, D. A., Davidson, C. A., Glatt, D. M., Roth, M. T., Gharkholonarehe, N. and Mumper, R. J., 2013. Pharmacy student engagement, performance, and perception in a flipped satellite classroom. American Journal of Pharmaceutical Education, 77(9), pp 196-204, DOI: 10.5688/ajpe779196.

McNally, B., Chipperfield, J., Dorsett, P., Del Fabbro, L., Frommolt, V., Goetz, S., Lewhol, J., Molineux, M., Pearson, A. Reddan, G., Roiko, A. and Rung, A., 2017. Flipped classroom experiences: student preferences and flip strategy in a higher education context. Higher Education, 73(2), pp. 281-298. doi:10.1007/s10734-016-0014-z

Myers, S. A., Edwards, C., Wahl, S. T., and Martin, M. M., 2007. The relationship between perceived instructor aggressive communication and college student involvement. Communication Education, 56(4), pp. 495-508. doi:10.1080/03634520701466398

Myers, S. A., Martin, M. M., and Knapp, J. L., 2005. Perceived instructor in-class communicative behaviors as a predictor of student participation in out of class communication. Communication Quarterly, 53(4), pp. 437-450. doi:10.1080/01463370500102046

Nadler, M. K., and Nadler, L. B., 2001. The roles of sex, empathy, and credibility in cut-of-class communication between faculty and students. Women's Studies in Communication, 24(2), pp. 241-261. doi:10.1080/07491409.2001.10162436

Nouri, J., 2016. The flipped classroom: for active, effective and increased learning - especially for low achievers. International Journal of Educational Technology in Higher Education, 13(1), pp 1-10, doi:10.1186/s41239-016-0032-z

O'Flaherty, J., and Phillips, C. (2015). The use of flipped classrooms in higher education: a scoping review. Internet and Higher Education, 25, pp. 85-95. doi:10.1016/j.iheduc.2015.02.002

Pardo, A., Gašević, D., Jovanovic, J., Dawson, S., and Mirriahi, N., 2019. Exploring student interactions with preparation activities in a flipped classroom experience. IEEE Transactions on Learning Technologies, 12(3), pp. 333-346.

Ryan, R. M., and Deci, E. L., 2000. Intrinsic and extrinsic motivations: classic definitions and new directions. Contemporary Educational Psychology, 25(1), pp. 54-67. doi:10.1006/ceps.1999.1020

Song, Y., and Kapur, M., 2017. How to flip the classroom--"productive failure or traditional flipped classroom" pedagogical design? Educational Technology and Society, 20(1), pp. 292-305.

Sullivan, S. M., 2016. The Effects of Prompting Metacognition using Email or Text Reminders on Student Participation, Persistence, and Performance in a Blended Course, Mobile,AL,USA: University of South Alabama.

Sung, C. C. M., 2018. Out-of-class communication and awareness of English as a lingua franca. ELT Journal, 72(1), pp. 15-25. 
Teo, I., and Arkoudis, S., 2019. Transitioning from a foundation studies program to university: a study of mainland Chinese students. Higher Education Research and Development, 38(4), pp. 864-877. doi:10.1080/07294360.2019.1576592

Thai, N. T. T., De Wever, B., and Valcke, M., 2017. The impact of a flipped classroom design on learning performance in higher education: looking for the best "blend" of lectures and guiding questions with feedback. Computers and Education, 107, pp. 113-126. doi: 10.1016/j.compedu.2017.01.003

Waldeck, J., Kearney, P., and Plax, T., 2001. Teacher e-mail message strategies and students' willingness to communicate online. Journal of Applied Communication Research, 29(1), pp. 54-70.

Young, S., Kelsey, D., and Lancaster, A., 2011. Predicted outcome value of E-mail communication: factors that foster professional relational development between students and teachers. Communication Education, 60(4), pp. 371-388. doi:10.1080/03634523.2011.563388

Zainuddin, Z., and Halili, S. H., 2016. Flipped classroom research and trends from different fields of study. International Review of Research in Open and Distance Learning, 17(3), pp. 313-340. 